\title{
Armazenamento de pêssegos cv. “Granada” em atmosfera controlada, visando ao transporte a longas distâncias
}

\author{
Storage of cv. “Granada” peach fruit in controlled atmosphere aiming the transport for long distances
}

\author{
Auri Brackmann ${ }^{\mathrm{I}}$ Bruno Cesar Silva Bordignon ${ }^{\mathrm{II}}$ Ricardo Fabiano Hettwer Giehl ${ }^{\mathrm{II}}$ Ivan Sestari ${ }^{\mathrm{II}}$ \\ Ana Cristina Eisermann ${ }^{\text {IV }}$
}

\section{RESUMO}

O objetivo deste trabalho foi determinar as condições mais adequadas de atmosfera controlada (AC) $e$ temperatura, para a manutenção da qualidade de pêssegos cv. "Granada" colhidos em dois estádios de maturação, visando ao transporte para mercados distantes, como a Europa. Os regimes de armazenamento avaliados foram: [1] frigoconservação em atmosfera natural $\left(20,8 \mathrm{kPa}\right.$ de $\mathrm{O}_{2}$ $+<0,5 \mathrm{kPa}$ de $\mathrm{CO}_{2}$ ); condições de atmosfera controlada (AC) com [2] 6,0kPa de $\mathrm{O}_{2}+15,0 \mathrm{kPa}$ de $\mathrm{CO}_{2}$; [3] 1,0kPa de $\mathrm{O}_{2}+$ $3,0 \mathrm{kPa}$ de $\mathrm{CO}_{2}$; [4] 1,0kPa de $\mathrm{O}_{2}+<0,5 \mathrm{kPa}$ de $\mathrm{CO}_{2}$, todos a $+0,5^{\circ} \mathrm{C}$; além da AC com [5] 2,0kPa $\mathrm{O}_{2}+5,0 \mathrm{kPa} \mathrm{CO} \mathrm{CO}_{2} \mathrm{a}+0,5^{\circ} \mathrm{C}$ $e$ [6] essa mesma condição $a-0,5^{\circ} \mathrm{C}$. Essas condições foram utilizadas para o armazenamento de frutos colhidos no estádio verdoengo e frutos colhidos meio-maduros. A colheita de pêssegos cv. "Granada" no estádio de maturação verdoengo (cor de fundo da epiderme esverdeada) é a mais adequada, por reduzir a incidencia de escurecimento interno e de podridões, sem afetar negativamente a qualidade físico-química dos frutos. Para períodos de armazenamento de até 25 dias, o armazenamento em atmosfera controlada não traz benefícios significativos, em relação ao armazenamento refrigerado em atmosfera normal.

Palavras-chave: exportação, estádios de maturação, qualidade.

\section{ABSTRACT}

This research was aimed at evaluating controlled atmosphere (CA) and temperature conditions for storing of $\mathrm{cv}$. Granada peach fruit harvested at two ripening stages aiming the transport of fruit for distant market, such as Europe. Treatments evaluated were six storage conditions and two

\begin{abstract}
ripening stages. The storage conditions were: [1] cold storage (20.8kPa de $\mathrm{O}_{2}+<0.5 \mathrm{kPa}$ de $\mathrm{CO}_{2}$ ); controlled atmosphere (CA) conditions with [2] $6.0 \mathrm{kPade} \mathrm{O}_{2}+15.0 \mathrm{kPa}$ de $\mathrm{CO}_{2}$; [3] $1.0 \mathrm{kPa}$ de $\mathrm{O}_{2}+3.0 \mathrm{kPa}$ de $\mathrm{CO}_{2}$; [4] $1.0 \mathrm{kPa}$ de $\mathrm{O}_{2}+<0.5 \mathrm{kPa}$ de $\mathrm{CO}_{2}$, all at $+0.5^{\circ} \mathrm{C}$. Moreover, $\mathrm{CA}$ with $2.0 \mathrm{kPaO} \mathrm{O}_{2}+5.0 \mathrm{kPa} \mathrm{CO}$ was evaluated both at [5] $+0.5^{\circ} \mathrm{C}$ and [6] $-0.5^{\circ} \mathrm{C}$. Fruits were harvested either at the breaking stage or at the half-ripe ripening stage and stored in the conditions cited above. The harvest of $c v$. Granada peaches in the breaking stage (greeny background color of the skin) is the most suitable, because although not affecting the physical and chemical quality, these fruits showed a reduced incidence of flesh browning and rot. For short-term storage (25 days), controlled atmosphere did not significantly improve fruit quality in relation to cold storage.
\end{abstract}

Key words: exportation, ripening stages, quality.

\section{INTRODUÇÃO}

A cultivar "Granada”, de duplo propósito, destinado à indústria e ao consumo in natura, produz frutos de tamanho grande, de polpa firme, aderente ao caroço e de sabor levemente doce-ácido e com mais de $40 \%$ da superfície de sua epiderme coberta pela cor vermelha (RASEIRA \& NAKASU, 1998). Em função dessas características, os frutos dessa cultivar enquadram-se na preferência dos consumidores europeus. Devido à época de maturação dos frutos da cv. "Granada", que ocorre na primeira quinzena de novembro, verifica-se baixa incidência de podridão

'Departamento de Fitotecnia, Universidade Federal de Santa Maria (UFSM), 97105-900, Santa Maria, RS, Brasil. E-mail: brackman@ccr.ufsm.br. Autor para correspondência.

"Programa de Pós-graduação em Agronomia, UFSM, Santa Maria, RS, Brasil.

IIIPrograma de Pós-graduação em Fisiologia e Bioquímica de Plantas da Escola Superior de Agricultura Luiz de Queiroz (ESALQ), Universidade de São Paulo (USP), Piracicaba, SP, Brasil.

${ }^{\mathrm{IV}}$ Curso de Agronomia, UFSM, Santa Maria, RS, Brasil. 
parda (Monilinia fructicola) e de mariposa-oriental (Grapholita molesta) (RASEIRA \& NAKASU, 1998), o que permite a colheita de frutos de boa qualidade, que poderiam ser exportados para os países europeus, pois, nesta época, estes estão no período de entressafra.

O pêssego, entre as frutas de clima temperado, é a mais perecível, devido ao seu elevado metabolismo pós-colheita (COELHO, 1994). O amadurecimento acelerado de pêssegos é responsável pela sua reduzida vida de prateleira, o que representa sérias restrições para um eficiente manuseio e transporte (BONGHI et al., 1999). Entre os fatores que afetam a qualidade, gerando perdas pós-colheita, estão a perda de firmeza da polpa e a ocorrência de podridões e de distúrbios fisiológicos. Considerando que o transporte aéreo é muito oneroso, a exportação de pêssegos por via marítima torna-se a alternativa economicamente viável. Entretanto, o período de transporte pode se prolongar por mais de três semanas, sendo, por isso, necessário estabelecer condições adequadas de armazenamento para a manutenção da qualidade dos frutos.

O armazenamento refrigerado, principal método utilizado para conservação de pêssegos, diminui o metabolismo e evita a sua rápida deterioração (BRACKMANN et al., 2003). No entanto, dependendo da temperatura e do período de armazenamento, podese verificar uma elevada perda de qualidade, devido à incidência de dano por frio (LURIE \& CRISOSTO, 2005). Dessa forma, a associação da baixa temperatura com técnicas complementares, como a atmosfera controlada (AC), tem sido estudada como alternativa para a redução desse problema. Resultados positivos do uso da AC sobre a redução da incidência de dano por frio têm sido obtidos (ZHOU et al., 2000; GIRARDI et al., 2005). No entanto, até o momento, nenhum estudo foi conduzido com o objetivo de estabelecer as condições de armazenamento mais adequadas para pêssegos cv. "Granada”.

Com relação ao melhor estádio de maturação, para se efetuar a colheita de pêssegos cv. "Granada”, as informações na literatura são escassas. Para pêssegos cv. “Eldorado”, a colheita dos frutos no estádio verdoengo é o mais adequado para a manutenção da qualidade após 24 dias de armazenamento (BRACKMANN et al., 2005).

O objetivo deste trabalho foi determinar as condições mais adequadas de atmosfera controlada (AC) e temperatura para a manutenção da qualidade de pêssegos cv. "Granada” colhidos em dois estádios de maturação, visando ao transporte marítimo para mercados externos.

\section{MATERIAL E MÉTODOS}

O experimento foi conduzido no Núcleo de Pesquisa em Pós-Colheita do Departamento de Fitotecnia da Universidade Federal de Santa Maria, sendo utilizados frutos provenientes do pomar comercial Santo Antônio, da empresa Firpo, localizado no município de Canguçu, RS. Os frutos foram colhidos em dois estádios de maturação: verdoengo (cor de fundo da epiderme esverdeada) e meio-maduro (cor de fundo da epiderme creme).

O delineamento experimental utilizado foi o inteiramente casualizado, em esquema bifatorial (6x2), sendo avaliadas seis condições de armazenamento e dois pontos de maturação para colheita. Cada tratamento foi constituído por quatro repetições, contendo 10 frutos. Os regimes de armazenamento avaliados foram: [1] frigoconservação em atmosfera natural (20,8kPa de $\mathrm{O}_{2}+<0,5 \mathrm{kPa}$ de $\left.\mathrm{CO}_{2}\right)$; condições de atmosfera controlada (AC) com [2] 6,0kPa de $\mathrm{O}_{2}+$ $15,0 \mathrm{kPa}$ de $\mathrm{CO}_{2}$; [3] 1,0kPa de $\mathrm{O}_{2}+3,0 \mathrm{kPa}$ de $\mathrm{CO}_{2}$; [4] $1,0 \mathrm{kPa}$ de $\mathrm{O}_{2}+<0,5 \mathrm{kPa}$ de $\mathrm{CO}_{2}$, todos a $+0,5^{\circ} \mathrm{C}$; além da $\mathrm{AC}$ com [5] 2,0 $\mathrm{kPa} \mathrm{O}_{2}+5,0 \mathrm{kPa} \mathrm{CO}_{2} \mathrm{a}+0,5^{\circ} \mathrm{C} \mathrm{e} \mathrm{[6]} \mathrm{essa}$ mesma condição a $-0,5^{\circ} \mathrm{C}$. Essas condições foram utilizadas para o armazenamento de frutos colhidos no estádio verdoengo e de frutos colhidos meio-maduros.

Antes do armazenamento, efetuou-se uma análise inicial de uma amostra de cada estádio de maturação. Os frutos colhidos no estádio verdoengo apresentavam 38,4N de firmeza da polpa, 8,4 ${ }^{\circ}$ Brix de sólidos solúveis totais (SST) e 10,02meq $100 \mathrm{~mL}^{-1}$ de acidez titulável, enquanto que os colhidos no estádio meio-maduro apresentavam 30,7N, 8,5³rix e 9,11meq $100 \mathrm{~mL}^{-1}$, respectivamente.

As condições de AC foram instaladas em minicâmaras experimentais, com volume de 180L, depois de estabilizada a temperatura de armazenamento, sendo efetuada mediante a injeção, nas minicâmaras, de nitrogênio $\left(\mathrm{N}_{2}\right)$, proveniente de um gerador de $\mathrm{N}_{2}$, que funciona pelo princípio PSA. Através da diluição com $\mathrm{N}_{2}$, reduziu-se a pressão parcial do $\mathrm{O}_{2}$ de acordo com o nível preestabelecido para cada tratamento. As pressões parciais de $\mathrm{CO}_{2}$ foram obtidas mediante a injeção deste gás, proveniente de cilindros de alta pressão, no interior das minicâmaras.

As pressões parciais dos gases $\left(\mathrm{O}_{2}\right.$ e $\left.\mathrm{CO}_{2}\right)$, durante o período de armazenamento, foram monitoradas e corrigidas por meio de um equipamento totalmente automatizado da marca KronenbergerClimasul $^{\circledR}$. A temperatura das câmaras frigoríficas foi regulada automaticamente através de termostatos eletrônicos. Além disso, foi monitorada diariamente 
através de termômetros de mercúrio de alta resolução inseridos na polpa de alguns frutos.

As análises laboratoriais foram realizadas em dois períodos: após 24 dias de armazenamento refrigerado e mais quatro dias de exposição dos frutos a $20^{\circ} \mathrm{C}$. Foram analisados os parâmetros: cor de fundo da epiderme, determinada mediante o uso de um colorímetro marca Minolta ${ }^{\circledR}$ pelo sistema LAB L*a*b*. Os resultados foram expressos pelo somatório de $\mathrm{a}^{*}+$ $\mathrm{b}^{*}$, sendo que, quanto maior esse valor, mais amarela estava à cor de fundo da epiderme do fruto; firmeza da polpa, obtida com o auxílio de um penetrômetro manual provido com uma ponteira de 7,9mm de diâmetro, sendo os valores expressos em Newton (N). Além disso, também foram analisados: sólidos solúveis totais (SST), determinados por refratometria, com compensação do efeito da temperatura e expressos em graus Brix; acidez titulável, determinada em uma amostra de $10 \mathrm{~mL}$ de suco, diluída em $100 \mathrm{~mL}$ de água destilada, titulada com solução de $\mathrm{NaOH} 0,1 \mathrm{~N}$ até atingir $\mathrm{pH} 8,1$, sendo os resultados expressos em meq $100 \mathrm{~mL}^{-1}$; incidência de podridões, determinada através da contagem dos frutos com lesões podres de diâmetro superior a $5 \mathrm{~mm}$; e ocorrência de escurecimento da polpa, avaliada através da contagem dos frutos que apresentavam sintomas visuais característicos desse distúrbio.

Os dados, expressos em porcentagem, foram transformados pela fórmula $\operatorname{arc}$.sen $\sqrt{x / 100}$, sendo posteriormente submetidos, com os demais, à análise da variância. As médias foram comparadas entre si pelo teste de Duncan, em nível de 5\% de probabilidade de erro.

\section{RESULTADOS E DISCUSSÕES}

Após 25 dias de armazenamento refrigerado, não houve interação significativa dos fatores condições de armazenamento e ponto de maturação para nenhum dos parâmetros avaliados.

Na saída da câmara, a síntese de etileno foi menor nos frutos armazenados em AC com 6,0 $\mathrm{kPa} \mathrm{O}_{2}+$ 15,0kPa CO (Tabela 1). A produção catalítica de etileno pode ser inibida por meio de altas pressões parciais de $\mathrm{CO}_{2}$, provavelmente pela inibição da síntese e/ou atividade da ACC sintase, uma das enzimas-chave na rota de síntese desse fito-hormônio (MATHOOKO et al., 2001). No entanto, após quatro dias a $20^{\circ} \mathrm{C}$, a síntese de etileno aumentou significativamente, independentemente das condições de armazenamento, possivelmente pela exposição dos frutos às mesmas condições de temperatura e pressões parciais de $\mathrm{O}_{2} \mathrm{e}$ $\mathrm{CO}_{2}$ (Tabela 1). Além disso, não foram observadas diferenças significativas entre frutos colhidos verdoengos e meio-maduros para esse parâmetro (Tabela 2). Resultados semelhantes foram observados por FERNÁNDEZ-TRUJILLO et al. (1998), para a cv. Paraguayo.

Tabela 1 - Atividade metabólica e firmeza da polpa de pêssegos cv. “Granada” após 25 dias de armazenamento, na saída da câmara, e mais quatro dias a $20^{\circ} \mathrm{C}$. Santa Maria, RS.

\begin{tabular}{|c|c|c|c|c|}
\hline \multirow[b]{2}{*}{$\mathrm{O}_{2}+\mathrm{CO}_{2}(\mathrm{kPa})$} & \multirow[b]{2}{*}{ Temperatura $\left({ }^{\circ} \mathrm{C}\right)$} & Síntese de etileno $\left(\mathrm{IL} \mathrm{kg}^{-1} \mathrm{~h}^{-1}\right)$ & Resniracão (mL & Firmezada nolna (N) \\
\hline & & \multicolumn{3}{|c|}{ Saída da câmara } \\
\hline $\mathrm{AR}^{1}$ & $+0,5^{\circ} \mathrm{C}$ & $5,19 \mathrm{~b}^{2}$ & 15,34 a & $28,3 \mathrm{ab}$ \\
\hline $6,0+15,0$ & $+0,5^{\circ} \mathrm{C}$ & $2,49 \mathrm{c}$ & $15,06 \mathrm{ab}$ & $30,6 a b$ \\
\hline $1,0+3,0$ & $+0,5^{\circ} \mathrm{C}$ & $7,16 a b$ & 11,59 c & 34,5 a \\
\hline $1,0+<0,5$ & $+0,5^{\circ} \mathrm{C}$ & 9,06 a & 12,88 bc & $33,5 \mathrm{ab}$ \\
\hline $2,0+5,0$ & $+0,5^{\circ} \mathrm{C}$ & $7,03 \mathrm{ab}$ & $13,63 \mathrm{~b}$ & $31,8 a b$ \\
\hline $2,0+5,0$ & $-0,5^{\circ} \mathrm{C}$ & $6,08 \mathrm{~b}$ & $12,24 \mathrm{c}$ & 27,3 b \\
\hline \multicolumn{2}{|c|}{ CV (\%) } & 22,27 & 10,85 & 12,70 \\
\hline \multicolumn{2}{|c|}{ Tratamentos } & \multicolumn{3}{|c|}{ Quatro dias a $20^{\circ} \mathrm{C}$} \\
\hline $\mathrm{AR}$ & $+0,5^{\circ} \mathrm{C}$ & 19,95 a & $18,15 \mathrm{a}$ & $24,5 \mathrm{a}$ \\
\hline $6,0+15,0$ & $+0,5^{\circ} \mathrm{C}$ & 15,89 a & $17,09 \mathrm{ab}$ & 25,7 a \\
\hline $1,0+3,0$ & $+0,5^{\circ} \mathrm{C}$ & 21,35 a & $12,96 \mathrm{c}$ & 26,7 a \\
\hline $1,0+<0,5$ & $+0,5^{\circ} \mathrm{C}$ & 21,41 a & 14,62 bc & $25,6 \mathrm{a}$ \\
\hline $2,0+5,0$ & $+0,5^{\circ} \mathrm{C}$ & 19,73 a & 15,35 b & $26,4 \mathrm{a}$ \\
\hline $2,0+5,0$ & $-0,5^{\circ} \mathrm{C}$ & 21,84 a & $16,33 \mathrm{ab}$ & 25,7 a \\
\hline \multicolumn{2}{|c|}{ CV (\%) } & 18,90 & 12,52 & 5,73 \\
\hline
\end{tabular}

${ }^{1} \mathrm{AR}$ = frigoconservação sob 21,0kPa $\mathrm{O}_{2}+<0,5 \mathrm{kPa} \mathrm{CO}$;

${ }^{2}$ Médias seguidas de mesma letra não diferem entre si pelo teste de Duncan em nível de 5\% de probabilidade de erro.

Ciência Rural, v.37, n.3, mai-jun, 2007. 
Tabela 2 - Qualidade físico-química e incidência de podridões e de distúrbios fisiológicos de pêssegos cv. “Granada” colhidos em dois pontos de maturação e armazenados durante 25 dias, na saída das câmaras e após quatro dias a $20^{\circ} \mathrm{C}$. Santa Maria, RS.

\begin{tabular}{|c|c|c|c|c|}
\hline \multirow{2}{*}{ Parâmetros } & Verdoengo & Meio-maduro & Verdoengo & Meio-maduro \\
\hline & \multicolumn{2}{|c|}{ Saída da câmara } & \multicolumn{2}{|c|}{ Quatro dias a $20^{\circ} \mathrm{C}$} \\
\hline Firmeza da polpa (N) & $34,97 a^{*}$ & $27,03 \mathrm{~b}$ & $27,39 \mathrm{a}$ & $24,14 \mathrm{~b}$ \\
\hline Acidez titulável (meq $100 \mathrm{~mL}^{-1}$ ) & 7,93 a & $7,26 \mathrm{~b}$ & 8,39 a & $7,05 \mathrm{~b}$ \\
\hline SST $\left({ }^{\circ}\right.$ Brix $)$ & 8,2 a & 8,1 a & 8,5 a & 8,4 a \\
\hline Cor de fundo $\left(a^{*}+b^{*}\right)$ & $50,60 \mathrm{~b}$ & 54,74 a & $62,17 \mathrm{~b}$ & 67,12 a \\
\hline Produção etileno $\left(\mu \mathrm{L} \mathrm{kg}^{-1} \mathrm{~h}^{-1}\right)$ & 6,03 a & $6,31 \mathrm{a}$ & 21,37 a & 18,69 a \\
\hline Respiração (mL CO kg $\left.^{-1} \mathrm{~h}^{-1}\right)$ & 12,95 a & 13,96 a & 15,55 a & 15,95 a \\
\hline Podridões (\%) & $1,5 \mathrm{a}$ & 3,0 a & 29,9 b & 46,3 a \\
\hline Escurecimento interno (\%) & $0,0 \mathrm{a}$ & 5,0 a & $11,1 \mathrm{~b}$ & 37,9 a \\
\hline
\end{tabular}

*Médias seguidas de mesma letra, na horizontal e dentro de cada momento de avaliação, não diferem entre si pelo teste de Duncan em nível de $5 \%$ de probabilidade de erro.

Menor respiração foi verificada nos frutos armazenados em AC com 1,0kPa de $\mathrm{O}_{2}+3,0 \mathrm{kPa}$ de $\mathrm{CO}_{2}$, tanto na saída da câmara, quanto após o período de exposição a $20^{\circ} \mathrm{C}$ (Tabela 1 ). Além disso, os frutos armazenados a $1,0 \mathrm{kPa}$ de $\mathrm{O}_{2}+<0,5 \mathrm{kPa}$ de $\mathrm{CO}_{2}$ e $2,0 \mathrm{kPa}$ de $\mathrm{O}_{2}+5,0 \mathrm{kPa}$ de $\mathrm{CO}_{2}$ a $-0,5^{\circ} \mathrm{C}$ também apresentaram baixa respiração na saída da câmara (Tabela 1). Tanto o baixo $\mathrm{O}_{2}$, quanto o alto $\mathrm{CO}_{2}$, afetam as reações de oxiredução envolvidas no processo de respiração (MAHAJAN \& GOSWAMI, 2001). A respiração dos frutos não foi afetada pelo estádio de maturação, em ambas as avaliações (Tabela 2), semelhante ao observado por FERNÁNDEZ-TRUJILLO et al. (1998), em pêssegos cv. "Paraguayo".

A firmeza da polpa, importante índice de maturação, manteve-se mais elevada nos frutos armazenados na $\mathrm{AC}$ com $1,0 \mathrm{kPa}$ de $\mathrm{O}_{2}+3,0 \mathrm{kPa}$ de $\mathrm{CO}_{2}$, diferindo somente dos frutos armazenados em AC a $0,5^{\circ} \mathrm{C}$ (Tabela 1). CERETTA et al. (2000) também determinaram como condição ideal, para a manutenção da firmeza de pêssegos cv. "Eldorado", o uso de AC com $1,0 \mathrm{kPa}$ de $\mathrm{O}_{2}$ e $3,0 \mathrm{kPa}$ de $\mathrm{CO}_{2}$. Após quatro dias a $20^{\circ} \mathrm{C}$, não houve diferença significativa entre os tratamentos para esse parâmetro (Tabela 3). Em relação ao ponto de maturação, os frutos colhidos verdoengos estavam mais firmes em ambas as avaliações (Tabela 2). Resultados semelhantes foram relatados para pêssegos cv. "BR1” e cv. "Eldorado” (GOTTINARI et al., 1998; BRACKMANN et al., 2005; respectivamente). Maior acidez titulável, na saída da câmara, foi observada nos frutos armazenados em AC com 2,0kPa de $\mathrm{O}_{2}+5,0 \mathrm{kPa}$ de $\mathrm{CO}_{2}$ a $-0,5^{\circ} \mathrm{C}$ (Tabela 4). Esse resultado deve-se, em parte, a baixa taxa respiratória desses frutos (Tabela 1), que deve ter reduzido o consumo dos ácidos orgânicos pelo ciclo dos ácidos tricarboxílicos (ETIENNE et al., 2002). Após quatro dias a $20^{\circ} \mathrm{C}$, a acidez titulável dos frutos foi semelhante, independentemente dos tratamentos (Tabela 3). Quanto ao ponto de maturação, a acidez apresentou valores maiores para os frutos colhidos no estádio verdoengo, na saída da câmara e após a exposição a $20^{\circ} \mathrm{C}$ (Tabela 2). Esses resultados estão em concordância com GOTTINARI et al. (1998) e BRACKMANN et al. (2005).

Tabela 3 - Incidência de podridões e de escurecimento interno em pêssegos cv. “Granada” após 25 dias de armazenamento e mais quatro dias a $20^{\circ} \mathrm{C}$. Santa Maria, RS.

\begin{tabular}{|c|c|c|c|}
\hline $\mathrm{O}_{2}+\mathrm{CO}_{2}(\mathrm{kPa})$ & Temperatura $\left({ }^{\circ} \mathrm{C}\right)$ & Frutos podres (\%) & Escurecimento interno (\%) \\
\hline $\mathrm{AR}^{1}$ & $+0,5^{\circ} \mathrm{C}$ & $29,0 \mathrm{~cd}^{2}$ & 29,2 a \\
\hline $6,0+15,0$ & $+0,5^{\circ} \mathrm{C}$ & 62,5 a & 30,6 a \\
\hline $1,0+3,0$ & $+0,5^{\circ} \mathrm{C}$ & 48,6 b & 23,6 a \\
\hline $1,0+<0,5$ & $+0,5^{\circ} \mathrm{C}$ & $29,2 \mathrm{~cd}$ & 22,0 a \\
\hline $2,0+5,0$ & $+0,5^{\circ} \mathrm{C}$ & 40,2 bc & 20,8 a \\
\hline $2,0+5,0$ & $-0,5^{\circ} \mathrm{C}$ & $18,9 \mathrm{~d}$ & 20,8 a \\
\hline \multicolumn{2}{|c|}{ CV (\%) } & 13,92 & 28,20 \\
\hline
\end{tabular}

${ }^{1} \mathrm{AR}=$ frigoconservação sob $21,0 \mathrm{kPa} \mathrm{O}+<0,5 \mathrm{kPa} \mathrm{CO}$;

${ }^{2}$ Médias seguidas de mesma letra não diferem entre si pelo teste de Duncan em nível de 5\% de probabilidade de erro. 
Essas diferenças devem-se, provavelmente, ao conteúdo diferenciado de ácidos orgânicos no momento da colheita, pois a taxa respiratória e a síntese de etileno dos frutos foram iguais, independentemente do ponto de colheita (Tabela 2).

As condições de armazenamento avaliadas não afetaram significativamente o conteúdo de sólidos solúveis totais dos frutos, na saída da câmara (Tabela 4). Entretanto, com a exposição a $20^{\circ} \mathrm{C}$ por quatro dias, os frutos armazenados na AC com 2,0kPa de $\mathrm{O}_{2}+5,0 \mathrm{kPa}$ de $\mathrm{CO}_{2}$ a $-0,5^{\circ} \mathrm{C}$ apresentaram teores de SST um pouco maiores (Tabela 4). Normalmente, não se percebem grandes alterações nos SST durante o armazenamento em atmosfera controlada, pois os açúcares passam a ser consumidos mais efetivamente na respiração, somente depois de acentuado consumo de ácidos orgânicos. Os estádios de maturação não influenciaram significativamente os teores de SST, em ambos os momentos de avaliação (Tabela 2), demonstrando um comportamento diferenciado de pêssegos cv. “Granada” em relação às cultivares "BR1” e "Eldorado" (GOTTINARI et al.,1998; BRACKMANN et al., 2005). Apesar de não influenciarem significativamente a cor de fundo da epiderme dos frutos, na saída da câmara, as condições de armazenamento com pressões parciais de $\mathrm{CO}_{2}$ mais elevadas (5,0 e 15,0kPa) mantiveram os frutos mais verdes após quatro dias a $20^{\circ} \mathrm{C}$ (Tabela 4). Para NAVA \& BRACKMANN (2002), as condições de AC com
0,8kPa de $\mathrm{O}_{2}+3,0 \mathrm{kPa}$ de $\mathrm{CO}_{2}$ e $1,0 \mathrm{kPa}$ de $\mathrm{O}_{2}$ associada a 4,0 e 5,0kPa de $\mathrm{CO}_{2}$ mantiveram a epiderme de pêssegos cv. "Chiripá” mais verde após oito semanas de armazenamento. Os pêssegos colhidos no estádio de maturação verdoengo mantiveram-se mais verdes que os meio-maduros, tanto na saída da câmara, quanto após a exposição a $20^{\circ} \mathrm{C}$ por quatro dias (Tabela 2 ).

A incidência de podridões foi extremamente baixa na saída da câmara, independentemente dos tratamentos (dados não apresentados). Após quatro dias a $20^{\circ} \mathrm{C}$, observou-se um aumento considerável na incidência de podridões, sendo que menor incidência foi obtida com o armazenamento em AC com 2,0kPa de $\mathrm{O}_{2}+5,0 \mathrm{kPa}$ de $\mathrm{CO}_{2} \mathrm{a}-0,5^{\circ} \mathrm{C}$ (Tabela 3). Em pêssegos cv. "Eldorado", essa mesma condição foi a mais eficiente no controle de podridões (BRACKMANN et al., 2005). Segundo AGAR et al. (1990), o crescimento de fungos pode ser retardado por meio da redução da temperatura e do aumento da pressão parcial de $\mathrm{CO}_{2}$. Os frutos colhidos no estádio verdoengo apresentaram menor incidência de podridões que os frutos colhidos meiomaduros, após quatro dias a $20^{\circ} \mathrm{C}$ (Tabela 2).

O escurecimento da polpa, principal distúrbio fisiológico em pêssegos de polpa amarela e firme (LURIE \& CRISOSTO, 2005), como os frutos da cultivar cv. “Granada”, foi pouco pronunciado na saída da câmara (dados não mostrados). No entanto, com a exposição dos frutos a $20^{\circ} \mathrm{C}$, a incidência dessa desordem fisiológica aumentou significativamente,

Tabela 4 - Qualidade físico-química de pêssegos cv. “Granada” após 25 dias de armazenamento, na saída da câmara, e mais quatro dias a $20^{\circ}$ C. Santa Maria, RS.

\begin{tabular}{|c|c|c|c|c|}
\hline \multicolumn{2}{|c|}{ Tratamentos } & Acidez titulável (meq 100 $\mathrm{ml}^{-1}$ ) & SST ( ${ }^{\circ}$ Brix) & Cor de fundo $\left(a^{*}+b^{*}\right)$ \\
\hline $\mathrm{O}_{2}+\mathrm{CO}_{2}(\mathrm{kPa})$ & Temperatura $\left({ }^{\circ} \mathrm{C}\right)$ & \multicolumn{3}{|c|}{ Saída da câmara } \\
\hline $\mathrm{AR}^{1}$ & $+0,5^{\circ} \mathrm{C}$ & $7,58 b^{2}$ & 8,3 a & $52,54 \mathrm{a}$ \\
\hline $6,0+15,0$ & $+0,5^{\circ} \mathrm{C}$ & $7,01 \mathrm{~b}$ & 7,9 a & 51,33 a \\
\hline $1,0+3,0$ & $+0,5^{\circ} \mathrm{C}$ & $7,30 \mathrm{~b}$ & $8,4 \mathrm{a}$ & 53,34 a \\
\hline $1,0+<0,5$ & $+0,5^{\circ} \mathrm{C}$ & $7,10 \mathrm{~b}$ & $8,0 \mathrm{a}$ & $52,35 \mathrm{a}$ \\
\hline $2,0+5,0$ & $+0,5^{\circ} \mathrm{C}$ & $7,00 \mathrm{~b}$ & 8,0 a & 54,62 a \\
\hline $2,0+5,0$ & $-0,5^{\circ} \mathrm{C}$ & 9,39 a & $8,3 \mathrm{a}$ & 52,16 a \\
\hline \multicolumn{2}{|c|}{ CV (\%) } & 6,69 & 5,46 & 6,24 \\
\hline \multicolumn{2}{|c|}{ Tratamentos } & \multicolumn{3}{|c|}{ Quatro dias a $20^{\circ} \mathrm{C}$} \\
\hline AR & $+0,5^{\circ} \mathrm{C}$ & 7,99 a & $8,3 \mathrm{~b}$ & 67,55 a \\
\hline $6,0+15,0$ & $+0,5^{\circ} \mathrm{C}$ & 7,76 a & $8,4 \mathrm{ab}$ & $61,75 \mathrm{~b}$ \\
\hline $1,0+3,0$ & $+0,5^{\circ} \mathrm{C}$ & 7,77 a & $8,3 \mathrm{~b}$ & $65,04 \mathrm{ab}$ \\
\hline $1,0+<0,5$ & $+0,5^{\circ} \mathrm{C}$ & 7,48 a & $8,5 \mathrm{ab}$ & 68,77 a \\
\hline $2,0+5,0$ & $+0,5^{\circ} \mathrm{C}$ & 7,38 a & $8,4 \mathrm{ab}$ & $62,72 \mathrm{~b}$ \\
\hline \multirow[t]{2}{*}{$2,0+5,0$} & $-0,5^{\circ} \mathrm{C}$ & 7,95 a & 8,6 a & $62,03 \mathrm{~b}$ \\
\hline & (\%) & 5,10 & 1,51 & 3,77 \\
\hline
\end{tabular}

${ }^{1} \mathrm{AR}=$ frigoconservação sob 21,0kPa $\mathrm{O}_{2}+<0,5 \mathrm{kPa} \mathrm{CO}$;

${ }^{2}$ Médias seguidas de mesma letra não diferem entre si pelo teste de Duncan em nível de $5 \%$ de probabilidade de erro. 
sendo que nenhuma condição de armazenamento foi eficiente no seu controle (Tabela 3). De acordo com LURIE \& CRISOSTO (2005), o escurecimento da polpa está relacionado a modificações na permeabilidade das membranas celulares, que podem permitir a interação dos compostos fenólicos com as polifenoloxidases. Além disso, a incidência de escurecimento da polpa em pêssegos está positivamente correlacionada com o quociente respiratório dos frutos, pois, quanto maior a taxa respiratória, mais alta é a incidência de escurecimento da polpa (STEFFENS et al., 2006). Em relação ao ponto de maturação, observou-se menor ocorrência de escurecimento interno nos frutos colhidos verdoengos (Tabela 2), similarmente aos resultados reportados por BRACKMANN et al. (2005). A influência do ponto de colheita sobre a incidência de dano por frio é dependente da cultivar e do tipo de desordem que está sendo avaliada (LURIE \& CRISOSTO, 2005).

\section{CONCLUSÕES}

A colheita de pêssegos cv. "Granada” no estádio de maturação verdoengo (cor de fundo da epiderme esverdeada) é a mais adequada, por reduzir a incidência de escurecimento interno e de podridões, sem afetar negativamente a qualidade físico-química dos frutos. Para períodos de armazenamento de até 25 dias, o armazenamento em atmosfera controlada não traz benefícios significativos, em relação ao armazenamento refrigerado em atmosfera normal.

\section{AGRADECIMENTOS}

Ao Conselho Nacional de Desenvolvimento Científico e Tecnológico (CNPq), pelo financiamento de parte deste projeto e pela concessão de bolsas aos pesquisadores Giehl e Eisermann.

\section{REFERÊNCIAS}

AGAR, T. et al. Effect of high $\mathrm{CO}_{2}$ and low $\mathrm{O}^{2}$ concentrations on the growth of Botrytis cinerea at different temperatures. Gartenbauwissenschaft, Berlin, v.55, n.5, p.219-222, 1990.

BONGHI, C. et al. Peach fruit ripening and quality in relation to picking time and hypoxic and high $\mathrm{CO}_{2}$ short-term postharvest treatments. Postharvest Biology and Technology, Amsterdam, v.16, p.213-222, 1999.

BRACKMANN, A. et al. Armazenamento de pêssego "Chimarrita” em atmosfera controlada e sob absorção de etileno. Ciência Rural, Santa Maria, v.33, n.3, p.431-435, 2003.

BRACKMANN, A. et al. Utilização da atmosfera controlada para o armazenamento de pêssegos "Eldorado" colhidos em dois estádios de maturação. Revista Brasileira de Armazenamento, Viçosa, v.30, n.2, p.209-214, 2005.

CERETTA, M. et al. Conservação em atmosfera controlada de pêssego cultivar Eldorado. Ciência Rural, Santa Maria, v.30, n.1, p.73-79, 2000

COELHO, A.H.R. Qualidade pós-colheita de pêssegos. Informe Agropecuário, Belo Horizonte, v.17, n.180, p.5-9, 1994.

ETIENNE, C. et al. Isolation and characterization of six peach cDNAs encoding key proteins in organic acid metabolism and solute accumulation: involvement in regulating peach fruit acidity. Physiologia Plantarum, Copenhagen, v.114, n.2, p.259-270, 2002.

FERNÁNDEZ-TRUJILLO J.P. et al. Physiological changes in peaches related to chilling injury and ripening. Postharvest Biology and Technology, Amsterdam, v.13, n.1, p.109-119, 1998.

GIRARDI, C.L. et al. Effect of ethylene, intermittent warming and controlled atmosphere on postharvest quality and the occurrence of woolliness in peach (Prunus persica cv. Chiripá) during cold storage. Postharvest Biology and Technology, Amsterdam, v.38, n.1, p.25-33, 2005.

GOTTINARI, R.A. et al. Frigoconservação de pêssego (Prunus persica (L.) Batsch) cV. BR1. Revista Brasileira de Agrociência, Pelotas, v.4, n.1, p.47-54, 1998.

LURIE, S.; CRISOSTO, C.H. Chilling injury in peach and nectarine. Postharvest Biology and Technology, Amsterdam, v.37, n.2, p.195-208, 2005

MAHAJAN, P.V; GOSWANI, T.K. Enzyme kinetics based modeling of respiration rate of apple. Journal of Agricultural Engineering Research, Amsterdam, v.79, n.4, p.339-406, 2001.

MATHOOKO, F.M. et al. Regulation of genes encoding ethylene biosynthetic enzymes in peach (Prunus persica L.) fruit by carbon dioxide and 1-methylcyclopropene. Postharvest Biology and Technology, Amsterdam, v.21, n.3, p.265-281, 2001.

NAVA, G.A.; BRACKMANN, A. Armazenamento de pêssegos "Chiripá” em atmosfera controlada. Revista Brasileira de Fruticultura, Jaboticabal, v.24, n.2, p.328-332, 2002.

RASEIRA, M.C.B.; NAKASU, B.H. Cultivares: descrição e recomendação. In: MEDEIROS, C.A.B.; RASEIRA, M.C.B. (Ed.). A cultura do pessegueiro. Brasília: EMBRAPA-SPI; Pelotas: Embrapa-CPACT, 1998. p.29-98.

STEFFENS C.A. et al. Escurecimento da polpa e respiração de pêssegos em função das condições de armazenamento. Revista Brasileira de Agrociência, Pelotas, v.12, n.1, p.71-75, 2006.

ZHOU, H-W. et al. Delayed storage and controlled atmosphere storage of nectarines: two strategies to prevent woolliness. Postharvest Biology and Technology, Amsterdam, v.18, n.1, p.133-141, 2000. 